\title{
Attack behavior in a multiple fixed-ratio schedule of reinforcement
}

\author{
RANDALL K. FLORY, Arizona State \\ University, Tempe, Ariz. 85281
}

Two pigeons were trained on a multiple, fixed-ratio schedule of reinforcement. When the key was red, a fixed-ratio 25 was in effect; when it was blue, a fixed-ratio 100 was in effect. Both pigeons consistently attacked a nearby stuffed pigeon only when the key color was blue even though such attack was not explicitly reinforced.

Exposure to such stimulus conditions as electric foot-shock or intense heat (Ulrich \& Azrin, 1962), electric shock to the tai (Azrin, Hutchinson, \& Sallery, 1964), and a physical blow (Azin, Hake, \& Hutchinson, 1965) will produce aggressive behavior in a number of different organisms. Recent experiments with pigeons (Azrin, Hutchinson, \& Hake, 1966), rats (Thompsoil \& Bloom, 1966), and monkeys (Hutchinson, Azrin, \& Hunt, 1968) establish as an attack-inducing condition the transition from high reinforcement frequency to extinction. Furthermore, monkeys will bite a nearby rubber tube (Hutchinson et al, 1968), and pigeons will attack another live but restrained pigeon (Gentry, 1968) during early portions of an intermittent food schedule. The purpose of the present study was to (1) further investigate the occurrence and differential schedule control of aggressive behavior in pigeons, and (2) to investigate the use of an inanimate object of attack.

\section{SUBJECTS}

Two male experimentally-naive White Carneaux pigeons served as experimental Ss. Each was maintained at $80 \%$ of its free-feeding body weight throughout the experiment. Both pigeons were housed in separate cages with water continuously available.

\section{APPARATUS}

The chamber in which daily sessions were conducted was similar to that described by Azrin, Hutchinson, \& Hake (1966). At one end of the sound-attenuated enclosure was a taxidermically-prepared White Carneaux pigeon. The head and throat areas of the stuffed model were covered with closely cropped white rabbit fur which resembled the downy feathers of these regions. The target pigeon was mounted on a mechanical arrangement such that a force of $35 \mathrm{~g}$ or more exerted against the model's head closed a microswitch. Such a switch closure defined an attack. Electrical and mechanical dampers decreased the occurrence of switch closures due to the bounce of the stuffed bird. Only switch closures separated by at least $1 \mathrm{sec}$ were recorded. The microswitch in turn operated counters and a cumulative recorder situated in an adjoining room.

\section{PROCEDURE}

Before the establishment of any experimental reinforcement history, both fooddeprived pigeons were exposed to the target bird for a $30 \mathrm{~min}$ period. During this baseline condition, the response key was inoperative and dark. The chamber was generally-illuminated by an overhead houselight. Next, the target pigeon was removed from the chamber. Both Ss were then magazine trained and shaped to peck the illuminated response key. Gradually, both birds were exposed to increasing fixed-ratio requirements. When the response key was red, every 25 th peck was reinforced by $4 \mathrm{sec}$ access to mixed grain. That is, a fixed-ratio 25 (FR 25) reinforcement schedule was in effect. When the key was blue, the grain was made available according to a fixed-ratio 100 schedule (FR 100). The fixed-ratio schedules and their correlated key colors alternated after each reinforcement. Daily sessions consisted of 60 grain deliveries.

Both pigeons were exposed to this multiple FR 25/FR 100 schedule with no target bird present until the behavior of each showed little variability over the last 5 of 15 sessions in this condition. Then the target pigeon was placed in the chamber, and both birds were exposed to the multiple schedule for a total of 21 sessions.

\section{RESULTS}

Neither bird made any attacks during the 30 -min baseline period preceding magazine training and shaping. The introduction of the stuffed pigeon following a reinforcement history on the multiple FR 25/FR 100, however, resulted in its being attacked by both Ss. Such attacks occurred, however, only when the response key was blue - the visual stimulus correlated with the FR 100 component of the multiple food schedule. Neither pigeon ever attacked the target bird when the key was red-the visual stimulus correlated with the FR 25 component.

Figure 1 presents records of a representative daily session for both Ss. Attacks (lower channel of each record) typically occurred during the pause preceding the stable, high-rate key-pecking behavior on the FR 100 schedule (upper channel of each record). Occasionally, a pigeon attacked after it had begun key pecking, but such instances were infrequent. Each pigeon was exposed to the multiple FR 25/FR 100 food schedule until attack number showed little systematic variability over five consecutive daily sessions as indicated by the SE of the mean. Based on these last five stable sessions, the mean per cent of FR 100 schedule components in which attack

Fig. 1. Representative records of a complete session for pigeons $S 1$ and $S 4$. The upper channel of each record shows key responding. Each response steps the recorder cumulatively, and each grain reinforcement resets the recorder. Attacks show as vertical hatch marks on the lower channel of each record. 
occurred was 49 for $S 1$ and 90 for S4. The mean number of attacks and SE of the mean for the same sessions were $34.0 \pm 2.8$ and $152.0 \pm 14.6$ for $S 1$ and $S 4$, respectively. The 5-day mean durations of the FR 25 and FR 100 schedule components were, respectively, $6.4 \mathrm{sec}$ and $48.6 \mathrm{sec}$ for $\mathrm{S} 1$ and $5.9 \mathrm{sec}$ and $46.7 \mathrm{sec}$ for $\mathrm{S} 4$.

Visual observation revealed that attacks were primarily directed toward the eyes, head, and throat areas of the target pigeon. Although attacks often included attempts at pulling out bits of rabbit fur, the target pigeon remained essentially undamaged throughout the experiment. Both Ss typically would not proceed to the stuffed model immediately after reinforcement of the FR 25 component. Rather, both birds would first orient themselves in front of the blue response key and then advance to the target bird.

\section{DISCUSSION}

The experiment supports the general observations of Hutchinson, Azrin, \& Hunt (1968) and Gentry (1968) that fixed-ratio food schedules generate concurrent aggressive behavior. The present data also support the finding of Hutchinson et al (1968) that attack behavior increased with increases in the fixed-ratio response requirement. That attack was generated by the FR 100 component but not by the FR 25 component of the multiple schedule suggests that a minimum response requirement and/or minimum reinforcement frequency per unit time is/are necessary for the production of aggressive behavior. It is also possible that the characteristic absence of pausing preceding FR 25 key pecking may have precluded the occurrence of attack in that component. Further analyses are needed.

It is unlikely that attack in the present study was maintained by superstitious reinforcement since attacks were temporally separated from subsequent reinforcement by a minimum of $47 \mathrm{sec}$ for $S 1$ and $41 \mathrm{sec}$ for S4. Furthermore, the occurrence of attack had no effect upon the probability of reinforcement since grain deliveries were dependent upon a specified number of key pecks rather than upon time elapsed since the last reinforcement. Finally, if attack behavior was being superstitiously maintained by grain deliveries, it should occur just before rather than following reinforcement.

The use of a durable inanimate attack object in the present study eliminated the problems encountered with a live target (cf. Azrin et al, 1966). The modified stuffed pigeon suggests a means for further objectifying and standardizing the analysis of aggressive behavior.

REFERENCES

AZRIN, N.H., HAKE, D. F., \& HUTCHINSON, R.
R. Elicitation of aggression by a physical blow. Journal of the Experimental Analysis of Behavior, 1965, 8, 55-57.

AZRIN, N.H., HUTCHINSON, R. R., \& HAKE, D. F. Extinction-induced aggression. Journal of the Experimental Analysis of Behavior, 1966, 9, 191-204.

AZRIN, N. H., HUTCHINSON, R. R., \& SALLERY, R. D. Pain-aggression toward inanimate objects. Journal of the Experimental Analysis of Behavior, 1964, 7, 223-227.

GENTRY, W. D. Fixed-ratio schedule-induced aggression. Joumal of the Experimental Analysis of Behavior, 1968, 11, 813-817.

HUTCHINSON, R. R., AZRIN, N.H., \& HUNT,G. $M$. Attack produced by intermittent reinforcement of a concurrent operant response. Journal of the Experimental Analysis of Behavior, 1968, $11,489-495$.
THOMPSON, T., \& BLOOM, W. Aggressive behavior and exinction-induced response-rate increase. Psychonomic Science, 1966, 5, 335-336.

ULRICH, R. E, \& AZRIN, N. H. Reflexive fighting in response to aversive stimulation. Journal of the Experimental Analysis of Behavior, 1962, 5, 511-520.

\section{NOTES}

1. This research was supported in part by Grant MH-11917 from NIMH to Arizona State University and in part by an Arizona State University graduate research fellowship to the author.

2. I thank Drs. Stanley S. Pliskoff and Aaron J. Brownstein for their assistance.

\section{Effects of blood-glucose levels on wheel-running activity of food-deprived rats'}

L. F. JAKUBCZAK, Gerontological Psychology Research Laboratory, Veterans Administration Hospital, Jefferson Barracks, St. Louis, Mo. 63125

The purpose of the two experiments was to determine whether or not changes in blood-glucose level affect wheel-running activity of food-deprived rats. Fructose, sucrose, adrenalin, insulin, and saline were injected into food-deprived rats, and their effects on wheel-running activity determined. Adrenalin and insulin decreased running activity, but fructose and sucrose did not. The results indicated that changes in blood-glucose level per se do not seem to be effective stimuli in the control of running activity of food-deprived rats.

Do changes in blood-glucose level play a role in the initiation or termination of running activity of food-deprived rats? Mayer (1955-56, p. 36) stated that the increased activity characteristic of "hunger" behavior is a frequently observed consequence of the depletion of carbohydrate reserves. Assuming that the glucose can be utilized by the peripheral tissue, eating occurs when blood-glucose utilization is low; as before a meal, and does not occur when it is high (Mayer, 1955-56). Since increases in restless and locomotor activity are correlated with the initiation of episodes of eating (Munn, 1950), changes in BGL may serve as stimuli in the control of activity. The purpose of these experiments was to determine whether or not changes in BGL affect wheel-running activity (RA) of food-deprived rats. The results of such experiments should shed light on one of the internal determinants of RA accompanying food deprivation.

\section{DESIGN}

Experiment 1 was carried out according to a 5 by 3 by 5 design (Type III, Linquist, 1956), representing five injected substances (fructose, sucrose, insulin, adrenalin, and normal saline); three blocks of rats formed on the basis of the amounts of running during the 7 days prior to injection; and five hourly samples of RA. The dependent variable for this and Experiment 2 was the number of wheel revolutions emitted during each successive hour of the experiment.

\section{SUBJECTS}

Forty-five male Sprague-Dawley rats (Holzman, Madison, Wis.) were used. Prior to deprivation, their weight was $298 \mathrm{~g}$ (S.D. $=7$ g; range: $284-311$ ).

\section{PROCEDURE}

The rats were randomly assigned to Wahmann activity wheels, deprived of food, and maintained at $80 \%$ of their initial weight. Water was available ad lib in the living compartment. The rats were locked in the wheel-drum for $6 \mathrm{~h}$ each day. At the end of $6 \mathrm{~h}$, they were removed, weighed, and locked in the living compartments for the remaining $18 \mathrm{~h}$. An hour after being removed from the drum, Ss received their food ration. This procedure was followed for 27 days. On the 28 th day, the rats were locked in the drum at their regular time. Two hours later, they were briefly removed, injected with the appropriate substances, returned to the drum, and locked in. The 